\title{
How New Computing Technology Reformed the Audit Profession
}

\author{
Bjørn Barth Jacobsen \\ University of Nordland \\ bjorn.barth. jacobsenestud.hibo.no
}

\begin{abstract}
This paper describes how the audit profession went through a paradigm restructuring itself, by taking advantage of ICT, which led to a wave of mergers from 1987 to 1998. The paper also presents two cases of fraud; the Kreuger and the Enron affairs. The latter led to the conviction of Arthur Andersen for obstruction of justice, which resulted in the termination of the company's activities, due to lack of confidence.
\end{abstract}

Keywords: Accounting, Andersen Consulting, audit, computing technology, Enron, fraud, ICT, Ivar Kreuger.

\section{Prologue}

When Ivar Kreuger committed suicide in March 1932, the Swedish government called upon the U.S. audit firm Price Waterhouse (PW), which revealed that a quarter of a billion dollars in assets did not exist. The largest case of fraud in history initiated the reformation process that created the U.S. Securities and Exchange Commission (SEC) in 1934. It was given authority to determine the improved accounting practices which became known as Generally Accepted Accounting Principles (GAAP) that provided auditors with the tools and authority to create order in the financial markets. These markets had been governed by animal spirits; irrational financial acts resembling casino behaviour.

In this historically-based text, I focus on the auditor, his roles and tools before and after World War II. One of the roles was to detect fraud. Pre-war auditors used mechanical bookkeeping machines such as Facit, Underwood, Olivetti, and IBM. How could these machines be trusted? In an old audit magazine I found the following statement from a Danish auditor, "the auditor cannot accept all mechanical calculations. All machines may fail in their automatic functions, and an operator may purposely manipulate the machines" [1]. He also advised that two independent accounts should be drawn up to improve controls, particularly when auditing banks and insurance companies.

The war brought new challenges to the audit profession, which contributed to the U.S. military efforts and spurred new approaches for achieving economic objectives and raising money. Increasingly complex wartime Treasury and IRS regulations in the U.S. resulted in specialized tax practices that diverged from GAAP. The logistics of war strained the mechanized pre-war clerical routines. Audit testing and internal 
control procedures were introduced in defence-related systems driven by tight deadlines and expanded the scope of work. New technology that could manage large amounts of information was required, which contributed to the development of the first electronic computers ENIAC \& EDVAC during 1943-47.

The wartime experience with computers provided a foundation for post-war accountants, transforming audit reporting systems into useful management tools. After the war, Price Waterhouse separated these activities into a Systems Department, the first consulting function of which, later named Management Advisory Services (MAS), staffed by specialists without an accounting background, contributed to a significant strategic change of the profession's direction. These professional consultants, attached to audit companies, were working for the government, large industries, banks, and insurance companies which required experts in hard- and software and applied system engineering.

The first commercial computer, UNIVAC I, was developed by Remington Rand (RR) and installed at the U.S. Bureau of Census in 1951, followed by forty-five units to governmental and business institutions. In 1953, General Electric hired MASconsultants from Arthur Andersen (AA), PW's main competitor, to program their first payrolls on the UNIVAC I.

The diversion into MAS changed the focus of AA's business, gradually reforming the firm's strategic concept. Specializing into computing consulting applications created a new profitable line of business. They aggressively used colour films in advertising to attract big clients and adopted a distinctive strategy into computing consulting. Their assertive approach transformed the audit profession. PW were concerned about the impact of MAS on the firm's relationship with audit clients and kept a lower profile than AA.

Remington Rand's UNIVAC became the leading mainframe for technical purposes, while IBM tailored their 700/7000 computers for business applications. The consulting wing of the auditing professions developed rapidly during the 1950s and 1960s. By the 1970s, it had become an important line of business, growing faster than the established auditing practice. AA took the lead among the Big Eight - also in Scandinavia.

Who was Arthur Andersen and why is he important in this historical context? His parents migrated to the U.S. from Denmark and Norway and died in 1901 when the ambitious youngster was sixteen. After graduating in 1908 as a Chartered Public Accountant (CPA), he worked for PW prior to starting on his own firm in Chicago in 1913. He left his mark on the profession long after his death in 1947. I have interviewed former auditors of AA who still refer to the firm as "Arthur." Let us therefore look at AA's audit and computing venture in Norway from the 1970s to illustrate how they developed new audit standards, computer applications, and institutional structures, as well as how they contended with fraud, attracted big clients, and promised ICT-improvements and better audit effectiveness.

\section{How AA Developed Computing into Scandinavian Audit in the 1970s}

AA was the largest auditing firm in Norway in 1970. Finn Berg Jacobsen, with a Harvard background, took the firm into computing at an early stage and recruited a 
core of talented engineers, economists, and auditors. He also engaged in fighting fraud, writing an article in 1977, "EDB-svindel" (Computing Fraud) [2]. The text illustrates AA's strategy in designing computer systems tailor-made to customers' needs. The extracts also show AA's marketing skills in making the clients dependent on their auditor's advice:

Computing fraud is a growing problem typically ten times larger than old-fashioned embezzlement, but so far they are quite rare in Norway. The problem with computing frauds is difficult to detect. There are three types:

- Financial crime, embezzling money or securities

- Information crime, including copying data or information

o Property crime, stealing assets or equipment.

Financial crime is a growing field for fraud. It is difficult for auditors to detect, due to lack of competence. In the U.S., three cases of computer fraud have recently been discovered that have cost the audit companies $\$ 39$ million in indemnity charges, paid from the auditors' insurance. This trend will obviously result in economic consequences for the profession. Information and property crime is also an expanding business where we need better computer competence and controls.

How do we protect ourselves against computer fraud? Computer Controls have to be part of the system design phase. Some claim that auditors ought to contribute to the system design. According to our standards, the auditor should not participate fully, but as a consultant. The auditor should limit activities to developing a control philosophy, advising when auditors should be actively engaged, and developing check-points where they should be consulted.

The role of auditors is important, but limited. Unnecessary discussions on computing technology is outside the scope of work for auditors, but consulting ought to be charged on separate accounts and fees. Auditors should, however, be key specialists with regards to efforts to expose fraud, according to the four phases of diagnosis illustrated below.

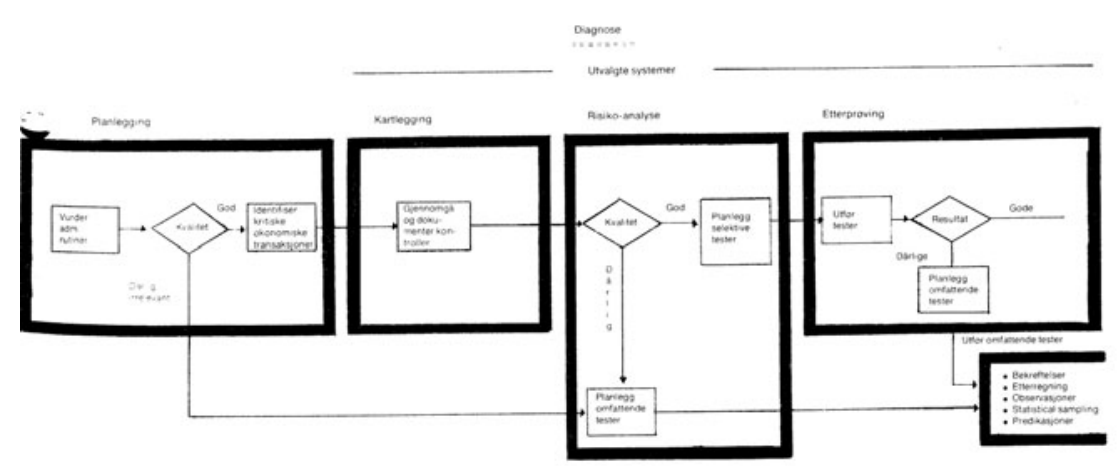

Fig. 1. Diagram illustrating how to prevent computing fraud. Extracts from article in Revisjon og Regnskap 3/77.

Berg Jacobsen's advice provides historical evidence about the status of computing, accounting, system consulting, and distinguishing the auditor's clean financial reports from their commercial activities. It introduces statistical sampling and risk-analyses, 
and identifies threats and weaknesses in critical transactions. The article introduces the term system revision, which audits the process more than the end product, the balance sheet.

He concludes that new professional demands require computer and audit technology as well as knowledge of the client's strengths and weaknesses. The auditor must also be able to motivate the client's employees into participating in risk-analyses and assessment. Due to the wide range of tasks, the auditor's advice is a teamwork approach, although this subject raises the question of the auditor's independence. $\mathrm{He}$ states that the risk of computer fraud is increasing. I interpret that remark as an important sales argument. Neither auditors nor their clients were normally covered by insurance.

He also remarks that computer software was designed for maximizing efficiency, not security. There was little fraud protection built into software. His punch line is that auditors who do not master risk-analyses could end up in prison, while the smart computer expert with fraudulent behaviour goes free. Control systems should be shifted from software to hardware and suppliers should design audit systems in a way that protects them from being manipulated by unauthorized personnel. The hidden message was clear; to avoid prison, engage AA as MAS-consultant and auditor. Those of us who worked with computers in the 1970s recognize the message. Tailor your own software and stay in control of your business using the minicomputer's competitive flexibility.

\section{1980s: ICT Shapes a New Paradigm for the Audit Profession}

MAS became a very profitable segment of growth for AA. The international audit firms emulated their strategies by using the audit function as an entrance ticket to lucrative ICT-contracts. PW, which had been represented in Norway and Sweden since 1933 in alliance with local firms, and in Denmark since 1948, was a hesitant follower, while Cooper \& Lybrand, which had established footholds in the Scandinavian market, was a professional contender for second place. The advent of minicomputers created a new segment when medium-size audit clients bought their own equipment, but lacked the expertise to run it. They all needed help.

In 1982-83, AA's chief ICT consultant in Norway, Arve Sogn Andersen, published several articles in the auditor's community magazine about the information revolution, micro-computers' application and experience, auditing with minicomputers, and how to choose systems. All the articles were illustrated with the AAtrademark and used tantalizing cartoons [3-7]. Mr Andersen had a professional technical background from Norsk Data and SI, a Norwegian research institute.

Throughout the 1980s, many computer engineers found interesting employment with the Scandinavian branches of the Big Eight. By 1983, the National Norwegian Audit Society had organized a computing committee, headed by Lasse Birkeland, a CPA and computing specialist partner in a small Oslo firm. He published three articles about auditing and minicomputers, focusing on statistics, the random selection of transactions, mathematical calculations, and so on $[6,7]$. 


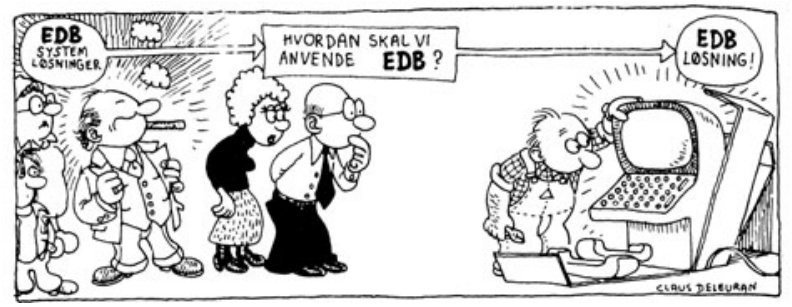

Fig. 2. AA cartoon promoting ICT-solutions for minicomputers

Lasse Birkeland also recommended using fantasy in the construction of software to take the drudgery out of the tedious work of the auditor. His articles won him fame and so much respect at AA that he was headhunted and sent to the U.S. to improve his computer competence. Returning to Norway, he presented a paper at the Nordic Auditor Congress in Gothenburg in August 1986, suggesting new methods to automate auditors work effectively. As a historian, the Gothenburg event seems to be a major shift of paradigm for ICT- systems for Scandinavian auditing. Birkeland coined his lecture as follows:

I hope I have given some ideas on how to use ICT as a tool for improving effectiveness in auditing. Furthermore, I hope we here in Gothenburg together can develop new Nordic solutions to common challenges. In this field, we will not be judged better than the weakest of us, by society and politicians. We must adapt to the new environments we shall be working in [8].

In hindsight, these words may sound prophetic. AA may have adapted too well to new times. ICT became a mixed blessing. From now on, computer transactions reduced the volume of manual control. This meant that the audit methods of using ledgers, checking cash transactions against paper files disappeared. The old auditor partners competed with young consultants dealing with clients; focus was on HW-terminals, ICT-systems, and new technology.

The new paradigm also created new opportunities for fraud, required improved monitoring systems, passwords, and so on, accelerating the importance of computer knowledge over audit judgement. Consulting practices within the major firms expanded dramatically. The complexity and applications of information and communication technology were no longer restricted to automating back office functions. New manufacturing methodologies required a new breed of non-CPA partners who advised clients about how to participate in global business development. Clients also asked the Big Eight to assist them in making use of electronic financial information. Computing technology was now essential for professional survival. It was also a rich source of profit.

The flip side was darker. It contained a hidden element of self-destruction. How? Consulting fees among Norwegian auditors had, by 1987, increased to 37 percent of revenues. Together with tax work, consulting fees were sometimes larger than audit fees. On a global scale, AA earned \$2 billion for designing and operating computing systems. MAS-consulting became a battlefield where the Big Eight competed with banks, lawyers, and financial planners on a global basis. The campaigns were fought 
by well-trained experts and specialists, the weapons were sophisticated software systems and the ability to interface with the client through the Trojan gate of audits.

The struggle between the auditor's independence and MAS-role created an internal conflict within each of the Big Eight audit firms. They were forced to grow with their clients' frantic hunt for global dominance, which led to a wave of mergers and acquisitions. It was a question of grow or die. The audit profession followed suit. This is the traditional historical explanation for the structural changes within the global auditing firms.

Another explanation is that the ICT-paradigm changed the audit processes. The routine manual work of checking transactional files against cash controls, which had earlier contributed to most of the income, vanished. Poorly paid manual work was replaced by computers, and the successful partners were the ones who gained status through highly paid consulting and advisory work. The big clients were conversant with high fees in the class of McKinsey, and Boston, among others, where they rarely complained about costs. The large audit firms now made their mark and money from MAS, and the Big Eight also emulated the consulting companies' organisational models. Young ambitious people climbed the steep career ladders, becoming partners before the age of thirty years. The old ones were stuck in a detour.

The merger processes commenced in 1984 with talks between PW and Deloitte, Haskins \& Sells. They were met with public resistance. PW then merged with Computech Corporation and with Consumer Finance Institute, combining computer systems with the analysis of financial planning programs. The results came quickly. By 1988, only 25 percent of PW's U.S. consultants were Chartered Accountants. The traditional audit was no longer their main focus, but used as an entryway for MASwork.

In 1986-87, Peat Marwick joined hands with European KMG to become the world's largest accounting organisation, KPMG. In Norway, they introduced themselves to customers in 1987, while KPMG became operative in Sweden by 1989, when it became affiliated with the highly respected audit firm Bohlins Revisionsbyrå, which had forebears as far back as 1923. Arthur Young and Ernst \& Whiney merged into Ernst \& Young and Deloitte formed a global firm with Touche in 1990.

The two largest companies, AA and PW, started to talk about a merger, but failed. Their company cultures were too different. There was also a growing conflict within AA about the distribution of profits from ICT-consulting, which led to a deep split among partners. A separate daughter company, Andersen Consulting, was created in 1989 and became an immediate success, which escalated the internal conflicts with AA, the parent company. Andersen Consulting integrated Management with ICT, in a very professional way. AA tried to combine the remains with audit independency. The two different lines of business were not compatible under a common umbrella, and the conflict was settled through arbitration in August 2000, when Andersen Consulting changed its name to Accenture.

AA continued on its own after the split, competing with its former daughter company. Driven by animal-like spirits, they now expanded into new consulting activities. Profits hovered between \$3-5 million and nearly doubled during 19962001. The dot.com-wave triggered opportunities for expansion where energy companies such as Enron was one of AA's most loyal clients. 
How could AA grow so fast? One historic explanation can be that the audit branch had become accustomed to the high income business, and the partners became greedy for greater profits. Without deeper reflection, they continued the consulting business to compete with the other major auditors. In order to stay in the competitive battle you had to be big. When the two remaining major audit firms, PW and Coopers \& Lybrand, merged in 1998 to become PwC, they created the world's largest integrated audit and service company with 150,000 employees, many of them ICT-experts.

AA's audit partners were continually encouraged to seek out opportunities for consulting fees from existing audit clients. By the late 1990s, AA had succeeded in tripling the per-share revenues of its partners. Predictably, AA struggled to balance the need to maintain its faithfulness to accounting standards with its clients' desire to maximize profits, particularly in the area of quarterly earnings reports. AA was alleged to be involved in the fraudulent auditing of several large international companies. Even other audit firms had problems during the dot.com-wave.

Computing technology had, in my opinion, transformed the audit firms by enabling them to control companies from the inside. By the end of the 1990s, the Finance Service Authorities in Norway reported that at some of the major audit firms consulting fees contributed as much as 70 percent of total revenues, most of it from MAS, ICT, and Tax Advisory work. The fees from clean audit reports were put under competitive pressure and such work was often provided free of charge to secure the bigger clients.

Another source of potential fraud was to assist in the valuation of airy assets. There were two types of valuation principles; historic value and fair value, the latter based on the estimation of future income. During the dot.com years, this was a risky activity governed by the hopes and animal-like spirits of the financial markets. The bubble economy was, by 2000 , no more solid than the optimistic times of 1929 which led to the Kreuger crash in 1932. Thus concludes my official story about computing.

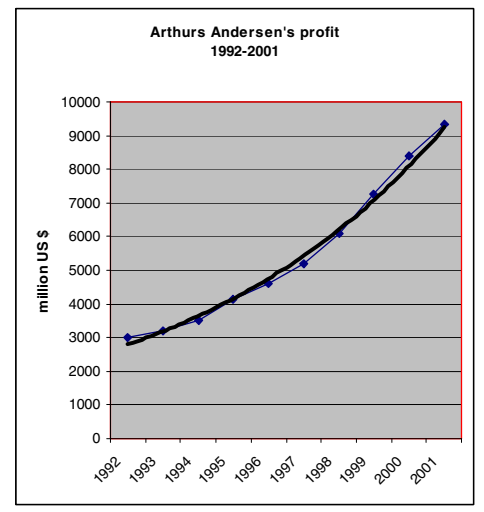

Fig. 3. AA's exponential growth before the Enron collapse 


\section{Epilogue: The End of Enron, AA, and Confidence in the Audit Profession}

This story about the manual and mechanical to electronic computing paradigm in the audit profession 1932-2001 has an epilogue. As a former electrical engineer who has actively worked with computers in the 1960s and 1970s at NTH, Shell, and Kongsberg, I have found pleasure preparing this paper and discovering that the field of computing contributed to the reformation of the audit profession.

Through the research, I discovered a story about fraud that was driven by what Keynes coined animal spirits, which ended in the collapse of the firm AA, for the same reasons. AA was, by 2001, in an enviable global position, having regained leadership after the split from its daughter company, Anderson Consulting. Its reputation as the one of the leading Big Five auditors of the world created a streak of arrogance that distinguished their corporate culture from the less assertive firms.

One of the biggest clients of their Houston office was Enron, which handsomely paid AA more than $\$ 50$ million annually to maintain the impression that their books were in order. They were not.

By concealing enormous loans and providing proof that the increasing profits were real, AA also helped Enron in persuading the stock market to believe that Enron's broadband plans were valued at $\$ 35$ billion, which supported the stock price of $\$ 90$ by the year 2000. One year later the company was broke. Loans fraudulently hidden and capitalizing on future profits were the popular songs that attracted investors. The similarity to the Kreuger case is striking. People could not believe it was true. By the end of October 2001, The New York Times wrote:

At the beginning of 2001, The Enron Corporation, the world's dominant energy trader, appeared unstoppable. The company's decade-long effort to persuade lawmakers to deregulate electricity markets had succeeded from California to New York. Its ties to the Bush administration assured that its views would be heard in Washington. Its sales, profits and stock were soaring.

Enron was bankrupt. AA was dismissed as Enron's auditor, citing the firm's accounting advice and the destruction of documents. AA countered that they had already severed ties with the company when Enron entered bankruptcy. But public confidence in AA vanished when the firm was charged with obstruction of justice and found guilty in June 2002 for shredding thousands of documents and deleting e-mails and company files that tied the firm to its audit of Enron. The conviction barred them from auditing public companies. The loss of the public's confidence frightened the remaining global auditors into withdrawing from MAS-consulting. PwC in Norway sold their consultancy group of 350 ICT experts to IBM.

Although only a small number of Arthur Andersen's employees were involved with the scandal, the firm was finished, and 85,000 employees lost their jobs. Most of the Nordic AA-people found new jobs with the remaining Big Four firms. Almost ten years later, the loss of public confidence and reputation is still a touchy subject among auditors. To restore confidence in the audit profession, the Sarbanes-Oxley Act was established by Congress in 2002, to protect investors against future accounting scandals. New regulations were also introduced in Europe. 
The audit profession is still struggling to re-establish its reputation. To this day, many people still have no faith in banking, insurance, as well as in their auditors, after the financial crisis of 2007. The global economy is as unstable as in the 1930s, driven by animal spirits and weak public regulation.

The trust in auditors and their tools - the computers - must be re-established. If we cannot trust our auditors and our banks, our money is not safe. My research thus far has, however, made me reasonably confident that we can restore faith in the audit profession and their ICT-solutions, if there is public pressure for transparency. So far, the profession seems to have a way to go.

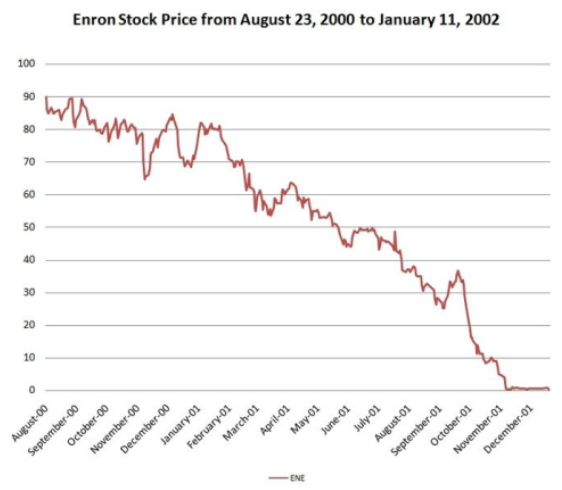

Fig. 4. Enron's share price 2000-2001

\section{References}

1. Revisjon og Regnskap. No. 2 (1980)

2. Revisjon og Regnskap. No. 3 (1977)

3. Revisjon og Regnskap. No. 6 (1982)

4. Revisjon og Regnskap. No. 8 (1982)

5. Revisjon og Regnskap. No. 2 (1983)

6. Revisjon og Regnskap. No. 4 (1983)

7. Revisjon og Regnskap. No. 6 (1983)

8. Revisjon og Regnskap. No. 7 (1986) 